\title{
The changing clinical profile of celiac disease: a 15-year experience (1998-2012) in an Italian referral center
}

\author{
Umberto Volta*, Giacomo Caio, Vincenzo Stanghellini and Roberto De Giorgio
}

\begin{abstract}
Background: Celiac disease is a multiform, challenging condition characterized by extremely variable features. Our goal was to define clinical, serological and histopathological findings in a large cohort of celiacs diagnosed in a single referral center.

Methods: From January 1998 to December 2012, 770 patients (599 females, median age 36 years, range 18-78 years) were diagnosed as celiacs at St.Orsola-Malpighi Hospital (Bologna, Italy). The clinical phenotypes were classified as: 1) classical (malabsorption syndrome); 2) non-classical (extraintestinal and/or gastrointestinal symptoms other than diarrhea); 3) subclinical. Serology, duodenal histology, comorbidities, response to gluten-free diet and complications were evaluated.

Results: Disease onset was symptomatic in 610 patients (79\%), while 160 celiacs showed a subclinical phenotype. In the symptomatic group the non-classical prevailed over the classical phenotype (66\% vs 34\%). Diarrhea was found in $27 \%$, while other gastrointestinal manifestations were bloating (20\%), aphthous stomatitis (18\%), alternating bowel habit (15\%), constipation (13\%) and gastroesophageal reflux disease (12\%). Extraintestinal manifestations included osteopenia/ osteoporosis (52\%), anemia (34\%), cryptogenic hypertransaminasemia (29\%) and recurrent miscarriages (12\%). Positivity for IgA tissue transglutaminase antibodies was detected in 97\%. Villous atrophy was found in $87 \%$, while $13 \%$ had minor lesions consistent with potential celiac disease. A large proportion of patients showed autoimmune disorders, i.e. autoimmune thyroiditis (26.3\%), dermatitis herpetiformis (4\%) and diabetes mellitus type 1 (3\%). Complicated celiac disease was very rare.
\end{abstract}

Conclusions: Our study demonstrates that the clinical profile of celiac disease changed over time with an increasing rate of non-classical and subclinical phenotypes.

Keywords: Celiac disease, Natural history, Clinical features

\section{Background}

Until the end of the second millennium, the classic view of celiac disease (CD) was that of a rare food intolerance characterized by villous atrophy and overt malabsorption mainly affecting pediatric patients. Recently, CD has markedly changed due to considerable advances in the knowledge of its pathogenic and diagnostic aspects $[1,2]$. CD is now an established autoimmune disorder triggered by gluten which activates an immune reaction against the $\mathrm{CD}$ autoantigen, i.e. tissue transglutaminase (TG2), in

\footnotetext{
* Correspondence: umberto.volta@aosp.bo.it

Department of Medical and Surgical Sciences, University of Bologna, S. Orsola-Malpighi Hospital, Bldg \#5 Via Massarenti 9, 40138 Bologna, Italy
}

genetically predisposed subjects [3]. The genetic susceptibility to CD is confirmed by its occurrence in about $10 \%$ of first-degree relatives and by its close linkage with histocompatibility leukocyte antigens (HLA)-DQ2 and -DQ8 [4]. Environmental factors such as breastfeeding, timing of weaning, viral/bacterial infections and microbiota changes can play a role in the onset of CD at any age [5-8].

The identification of biomarkers, e.g. antibodies to endomysium (EmA) [9] and to TG2 (anti-TG2) [10], has changed the epidemiology of $\mathrm{CD}$ from a rare to a frequent condition with an expected prevalence higher than $1 \%$ in the worldwide population. Nonetheless, the majority of patients with $C D$ remain undiagnosed leaving the celiac 
'iceberg' still submerged [11]. Serological screening has allowed an early CD diagnosis in its preclinical stage with the result that symptom presentation has radically changed compared to the past [12,13]. Indeed, CD is less commonly detected in patients with diarrhea, rather it occurs frequently in patients with other gastrointestinal symptoms, i.e. constipation and bloating, as well as with extra-intestinal manifestations and even in asymptomatic patients [14]. The different mode of presentation has led experts to elaborate the Oslo classification which subdivides CD in symptomatic, i.e. "classical" and "non-classical", vs. clinically silent, i.e. "subclinical", phenotypes [15].

In this study we retrospectively examined the clinical presentation of a large cohort of consecutive $\mathrm{CD}$ adult patients diagnosed in a single Italian referral center during a 15-year period. Our primary goal was to verify whether non-classical and subclinical CD increased over time compared to the classical CD. Furthermore, we aimed to define serology, histopathology, response to gluten free diet (GFD) and occurrence of complications in CD.

\section{Methods}

This is a retrospective paper assessing patients from January 1998 to December 2012: 770 CD patients (599 females, F/M ratio 3.5:1, median age at diagnosis 36 years, range 18-78 years) were consecutively diagnosed at the referral center of St. Orsola-Malpighi University Hospital (Bologna, Italy). All patients included in the study gave written informed consent to publish their own data when they were referred to our outpatient clinic for the first time. The diagnosis relied on duodenal biopsy and serology as well as HLA typing when indicated. Small intestinal biopsies ( $\mathrm{n}=5$ samples), taken from the bulb and the second duodenal portion, were classified according to Marsh-Oberhüber [16]. Serology included IgA antiTG2 and EmA together with IgG anti-TG2 or deamidated gliadin peptide antibodies (DGP) in the case of IgA deficiency [17]. Genetic testing, performed when there was a discrepancy between histology and serology as well as in selected cases, assessed HLA-DQ2 and-DQ8. The finding of villous atrophy (including partial - 3a -, subtotal $3 \mathrm{~b}$-, total atrophy - 3c) and positive serology confirmed $\mathrm{CD}$, whereas cases with positive serology and normal or mild intestinal lesions (increased intra-epithelial lymphocytes - IEL - i.e. lesion type 1) were classified as potential CD if HLA-DQ2 and/or -DQ8 tested positive. Cases with villous atrophy, negative serology and positivity for HLADQ2 and/or -DQ8 were confirmed as CD when a second intestinal biopsy showed villous regrowth after 1-year of GFD.

According to the Oslo classification, patients were classified as: 1) classical CD with malabsorptive syndrome, i.e. diarrhea and weight loss irrespective of extraintestinal manifestations; 2) non-classical CD with gastrointestinal symptoms (except for diarrhea) and extraintestinal manifestations; 3) subclinical CD for clinically silent cases or with symptoms below the threshold of detection [15].

Moreover, CD patients were investigated for pathologies known to be frequently associated with CD (including Hashimoto's thyroiditis, type 1 diabetes mellitus -DM), autoimmune liver disorders, connective tissue diseases, neurological, allergic and chromosomal disorders) and were followed up for the response to GFD and the occurrence of complications [18].

Since patients were not individually identified, a simplified International Review Board approval by the Ethics Committee of the St. Orsola Malpighi Hospital was obtained.

\section{Statistical analysis}

Statistical analysis was performed by applying Mann Whitney U test to compare: 1) age of patients at diagnosis in symptomatic (classical and non-classical) vs. subclinical $\mathrm{CD}$, as well as classical vs. non-classical phenotypes; 2) age of patients at diagnosis in seropositive and seronegative $\mathrm{CD} ; 3)$ age of patients at diagnosis in complicated vs. noncomplicated CD. Moreover, the Pearson Chi-square test was used to compare the clinical phenotype in seropositive vs. seronegative $C D$ patients and in complicated vs. noncomplicated CD. The above-mentioned statistical evaluations were carried out by means of Graphpad Instant Version3.0a (Graphpad Software Inc., San Diego, CA, USA).

\section{Results}

\section{Clinical data}

The annual distribution of CD diagnoses is shown in Figure 1. Of the $770 \mathrm{CD}$ patients, 318 were diagnosed in the first 10 years (1998-2007), whereas 452 were detected in the last five years (2008-2012). The onset of CD was symptomatic in 610 patients (79\%), whereas the remaining 160 (21\%) showed a subclinical phenotype. Of the 610 symptomatic patients, 210 had the classical phenotype, whereas 400 displayed the non-classical phenotype (Figure 2). In the period 1998-2007 the classical, nonclassical and subclinical phenotype were respectively found in $47.2 \%, 43.1 \%$ and $9.7 \%$ of CD cases, whereas in the period 2008-2012, the most frequent clinical phenotype was the non-classical (58.2\%), followed by the subclinical $(28.5 \%)$ and by the classical (13.3\%). The median age at diagnosis was significantly lower in patients with the subclinical (32 years) than with the symptomatic phenotype (37 years) $(P<0.001)$. No significant difference was found in the median age at diagnosis between classical and non-classical forms (39 vs. 36 years, $P=0.058$ ). Taking into account all CD patients $(n=770)$, about half $(53 \%)$ of them had gastrointestinal symptoms/manifestations, i.e. diarrhea (27\%), bloating (20\%), aphthous stomatitis (18\%), alternating bowel habit (15\%), constipation (13\%) and 


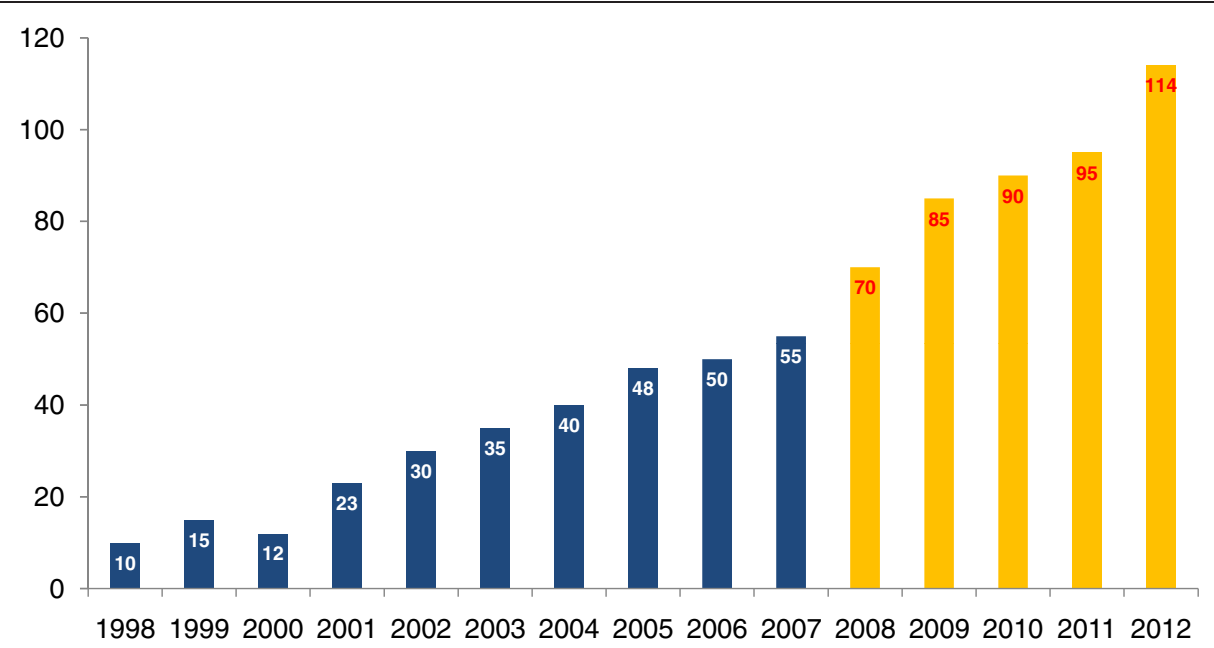

Figure 1 The annual distribution of CD diagnoses in the referral center of the St. Orsola-Malpighi University Hospital from 1998 to 2012. Of the 770 diagnosed patients, 318 (41.2\%) were identified in the first 10 years (1998-2007), whereas the other 452 (58.8\%) were diagnosed in the last five years (2008-2012).

gastroesophageal reflux disease (GERD) (12\%) (Figure 3A). Extra-intestinal manifestations, alone or in combination with gastrointestinal symptoms, were detected in $45 \%$ of $\mathrm{CD}$ patients (Figure 3B). Frequent findings were anemia (34\%), cryptogenic hypertransaminasemia (29\%) and recurrent miscarriages (12\%). A few CD patients showed IgEmediated allergy (9\%), often characterized by positivity for specific IgE to graminaceae and mites. A small number of subjects showed headache (5\%) and fibromyalgia-like symptoms $(2.2 \%)$. Iron-deficiency with low levels of ferritin was found in $85 \%$ of patients with anemia, which was also related to folic acid malabsorption. Bone densitometry, performed in two-thirds of the $770 \mathrm{CD}$ patients, revealed a condition of osteopenia/osteoporosis in $52 \%$ of cases, often associated with 25-OH Vitamin D3 low levels.

\section{Serological tests}

A total of 744 (97\%) out of the $770 \mathrm{CD}$ patients were positive for IgA anti-TG2, whereas $91 \%$ of the same patients were IgA EmA positive. EmA detection was always coincident with anti-TG2 positivity. Of the 26 patients negative for IgA anti-TG2 and EmA, 15 had selective IgA deficiency and all of them were positive for IgG anti-TG2 or DGP. Only $11 \mathrm{CD}$ patients (9 females) were seronegative. The median age at $\mathrm{CD}$ diagnosis was significantly higher in the seronegative vs. seropositive patients ( 49 vs. 36 years, $P<0.005$ ). Compared to seropositive cases, $\mathrm{CD}$ patients testing negative for serology were all characterized by a significantly higher prevalence of classical phenotype $(P<0.001)$. Four seronegative patients showed a positivity for first generation gliadin antibodies of IgG

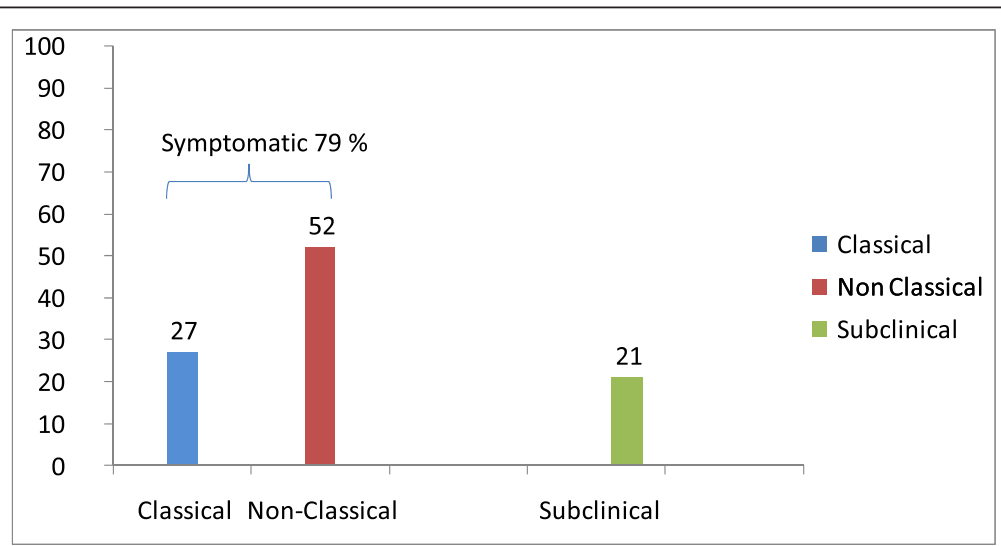

Figure 2 Prevalence of symptomatic and subclinical phenotypes in the $\mathbf{7 7 0}$ CD patients. Note that 610 patients (79\%) were diagnosed as symptomatic, whereas the remaining 160 (21\%) were classified as subclinical CD. Of the 610 symptomatic patients, 210 (34\%) displayed the classical onset with diarrhea and malabsorption (regardless of extraintestinal manifestations), whereas the other 400 showed the non-classical form with gastrointestinal symptoms (other than diarrhea) and extraintestinal manifestations. 

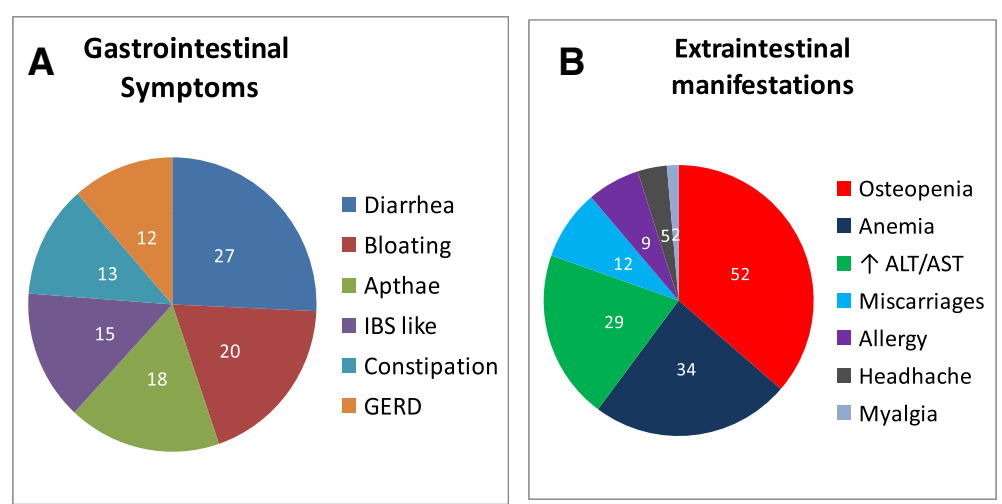

Figure 3 Gastrointestinal and extraintestinal symptoms in $\mathbf{7 7 0 ~ C D ~ p a t i e n t s . ~ A ) ~ S y m p t o m s ~ r e l a t e d ~ t o ~ g a s t r o i n t e s t i n a l ~ t r a c t ~ i n c l u d e d ~ d i a r r h e a ~}$ (27\%), bloating (20\%), aphthous stomatitis (18\%), alternate bowel habit (15\%), constipation (13\%) and gastroesophageal reflux disease (GERD) (12\%). B) Extraintestinal manifestations, alone or in combination with gastrointestinal symptoms/signs, included osteopenia/osteoporosis (52\%), anemia (34\%), cryptogenic hypertransaminasemia (29\%), recurrent miscarriages (12\%), lgE-mediated allergy (9\%), headache (5\%) and fibromyalgia-like symptoms (2.2\%).

class ( 1 case also associated with IgA), nowadays no longer considered serological CD markers (Table 1).

\section{Duodenal histology}

Villous atrophy was found in $670(87 \%)$ of $770 \mathrm{CD}$ patients. Total (3c) and subtotal (3b) villous atrophy were observed in $36 \%$ and in $26 \%$ of cases, respectively, whereas a partial (3a) atrophy was identified in $25 \%$ of patients. The remaining 100 patients (13\%) had a histological pattern characterized by an increased number of IEL (lesion type 1). These minor lesions were consistent with a potential CD, confirmed by HLA-DQ2 and/or -DQ8 and IgA anti-TG2 and/or EmA positivity. A high number of potential $C D$ were first-degree relatives of $C D$ and type $1 \mathrm{DM}$ patients. Only symptomatic cases of potential CD started
GFD, whereas subclinical cases continued to eat gluten. Five out of the 100 potential CD cases showed disappearance of EmA and anti-TG2 on a gluten containing diet.

\section{Associated disorders}

Autoimmune thyroiditis was found in $26.3 \%$ of CD patients, of whom about half showed hypothyroidism. Dermatitis herpetiformis was found in $4 \%$ of CD cases, whereas type $1 \mathrm{DM}$ was detectable in $3 \%$ of patients. Other associated diseases included neurological disorders, i.e. gluten ataxia, cryptogenic epilepsy and peripheral neuropathy (all together 2.2\%); IgA deficiency (1.9\%); autoimmune liver disorders, such as primary biliary cirrhosis and autoimmune hepatitis (1.8\%). Finally, connective tissue disorders, mainly Sjögren syndrome and systemic

Table 1 Clinical presentation, histology, genetics and associated disorders in patients with seronegative celiac disease

\begin{tabular}{|c|c|c|c|c|c|c|c|c|c|}
\hline \multirow[t]{2}{*}{ Pts } & \multirow[t]{2}{*}{ Gender } & \multirow{2}{*}{$\begin{array}{l}\text { Age at } \\
\text { diagnosis }\end{array}$} & \multirow{2}{*}{$\begin{array}{l}\text { Clinical } \\
\text { phenotype }\end{array}$} & \multirow{2}{*}{$\begin{array}{l}\text { HLA- } \\
\text { typing }\end{array}$} & \multicolumn{2}{|c|}{ Duodenal biopsy } & \multirow{2}{*}{$\begin{array}{l}\text { Anti-TG2 } \\
\text { EmA DGP }\end{array}$} & \multirow[t]{2}{*}{ AGA } & \multirow[t]{2}{*}{ Associated disorders } \\
\hline & & & & & Untreated & After GFD & & & \\
\hline$\# 1$ & Male & 58 & Classical & $\mathrm{DQ} 2+$ & $3 c$ & 1 & $\mathrm{Neg}$ & $\lg G+v e$ & Autoimmune thyroiditis \\
\hline$\# 2$ & Female & 34 & Classical & $\mathrm{DQ} 2+$ & $3 a$ & 1 & Neg & $\lg G+v e$ & PBC \\
\hline \#3 & Female & 37 & Classical & $\mathrm{DQ} 2+$ & $3 c$ & 1 & Neg & Neg & None \\
\hline \#4 & Female & 75 & Classical & DQ2+ & $3 c$ & 1 & Neg & Neg & None \\
\hline$\# 5$ & Female & 45 & Classical & $\mathrm{DQ} 2+$ & $3 a$ & 1 & Neg & Neg & None \\
\hline$\# 6$ & Female & 55 & Classical & $\mathrm{DQ} 2+$ & $3 c$ & 1 & Neg & $\lg G+v e$ & Gluten ataxia \\
\hline \#7 & Male & 61 & Classical & DQ8+ & $3 b$ & 1 & Neg & Neg & Peripheral neuropathy \\
\hline \#8 & Female & 48 & Classical & $\mathrm{DQ} 2+$ & $3 c$ & 1 & Neg & Neg & None \\
\hline \#9 & Female & 49 & Classical & DQ2+ & $3 a$ & 1 & Neg & $\lg G+v e ; \lg A+v e$ & Autoimmune gastritis \\
\hline$\# 10$ & Female & 30 & Classical & DQ2+ & $3 b$ & 1 & Neg & Neg & None \\
\hline \#11 & Female & 63 & Classical & DQ2+ & $3 c$ & 1 & Neg & Neg & None \\
\hline
\end{tabular}

Note: Anti-TG2: tissue transglutaminase antibodies, EmA: endomysial antibodies, DGP: deamidated gliadin antibodies, AGA: gliadin antibodies, GFD; gluten-free diet, PBC; primary biliary cirrhosis; duodenal biopsy scored according to Marsh-Oberhüber classification: "3a", partial; "3b", subtotal; "3c", total villous atrophy; "1" indicates increased intraepithelial lymphocytes. 
sclerosis were diagnosed in $1.7 \%$. Chromosomal disorders coexisted in $15 \mathrm{CD}$ patients, i.e. 12 Down and 3 Turner syndrome. Only three celiac patients were affected by inflammatory bowel disease (1 case of Crohn's disease ad 2 of ulcerative colitis).

\section{Non-responsive CD}

A total of 654 (85\%) of the $770 \mathrm{CD}$ patients underwent a clinical and biochemical follow-up every 18 months. The follow-up duration ranged from 18 months to 14 years (mean 5 years). The response to GFD was regarded as good in 514 patients (79\%), whereas the remaining $140 \mathrm{CD}$ cases showed a poor response to GFD and were labeled as non-responsive $\mathrm{CD}$. The main causes of non-responsive CD were poor compliance with GFD (40\%), irritable bowel syndrome (20\%), GERD (15\%), lactose intolerance (12\%), bacterial overgrowth (9\%) and complicated CD (4\%).

\section{Complicated CD}

Six $(0.9 \%)$ of the 654 CD patients developed complications during the follow-up (Table 2). Three patients had refractory CD type 1 , two had small bowel carcinoma and one developed enteropathy associated $\mathrm{T}$ cell lymphoma (EATCL). Patients developing complications had a late diagnosis with a median age of $C D$ at diagnosis significantly higher than that of non complicated CD (53.5 vs. 36 years, $P<0.005)$. The estimated diagnostic delay in complicated CD cases ranged from 5 to 11 years. All complicated $\mathrm{CD}$ had a classical phenotype testing positive for HLA-DQ2 (3 cases carried DQ2 in homozygosis). Regarding clinical presentation, classical phenotype was significantly higher in complicated vs. non complicated CD $(P<0.001)$ (Table 2$)$. Of the 6 complicated patients, 5 are still alive and only 1 with small bowel carcinoma died 2 years after surgery and chemotherapy.

\section{Discussion}

The present study defines the clinical, serological and histopathological features of $\mathrm{CD}$ in a large, singlecenter series of consecutively diagnosed patients. Our data highlighted a significant upward trend of diagnoses over time. In the last 5 years the number of $C D$ diagnoses was one and half times higher than that in the previous ten years. The clinical presentation of CD changed over time with a marked decrease of the classical phenotype (from $47.2 \%$ in the first 10 years to $13.3 \%$ in the last five years) and with a striking increase of the non-classical and subclinical phenotype which characterized the onset of CD in more than $86 \%$ of cases in the last five years. CD was more frequently found in females with a female/male ratio of 3.5:1, a figure that confirms well established data [19]. The median age of CD at diagnosis was between the third and the fourth decade of life, but $5 \%$ of our patients were diagnosed in the elderly. These late-onset cases, which were not explained as diagnostic delay, confirm that the disease can occur at any age [20]. CD patients were clinically stratified on the basis of the Oslo classification and, accordingly, the vast majority (79\%) were symptomatic. One third showed the classical form of the disease characterized by diarrhea and malabsorption, while the remaining two thirds were labeled as non-classical complaining of atypical gastrointestinal and extraintestinal manifestations. Notably, diarrhea should be no longer regarded as the cardinal symptom of CD [13]. Although there are no comparative studies on the prevalence of symptoms/manifestations (e.g., bloating, alternating bowel habit, constipation and GERD) in functional bowel disorders and CD patients, we demonstrated such symptoms in about $20 \%$ of cases suggesting a link between gastrointestinal functional impairment and CD. Confirmatory screening tests for CD should be proposed to patients with functional bowel symptoms, in particular to those people living in areas with high CD prevalence [21]. Frequent extraintestinal manifestations raising suspicion of CD were anemia (due to iron and, less frequently, folic acid deficiency), cryptogenic hypertransaminasemia and recurrent miscarriages. An unexplained osteopenia/osteoporosis was an indicator of $\mathrm{CD}$, being present in more than $50 \%$ of cases. One fifth of the $770 \mathrm{CD}$ patients were classified as having subclinical $C D$. This subgroup has progressively increased in recent years due to the use of serological

Table 2 Clinical and genetic features of the 6 celiac disease patients developing complications

\begin{tabular}{|c|c|c|c|c|c|c|c|c|}
\hline Pts & Gender & Age at diagnosis (yrs) & $\begin{array}{l}\text { Clinical } \\
\text { phenotype }\end{array}$ & HLA & $\begin{array}{l}\text { Delay in CD } \\
\text { diagnosis (yrs) }\end{array}$ & Age at complication (yrs) & Complication & Outcome \\
\hline$\# 1$ & M & 42 & Classical & $\mathrm{DQ} 2+{ }^{\circ}$ & 8 & 45 & EATCL & Alive, 54 yrs \\
\hline \#2 & $\mathrm{F}$ & 66 & Classical & DQ2+ & 10 & 70 & RCD type 1 & Alive, 73 yrs \\
\hline \#3 & $\mathrm{F}$ & 52 & Classical & $\mathrm{DQ} 2+{ }^{\circ}$ & 5 & 56 & RCD type 1 & Alive, 64 yrs \\
\hline$\# 4$ & $\mathrm{~F}$ & 48 & Classical & DQ2+ & 6 & 51 & Small bowel carcinoma & Dead, 53 yrs \\
\hline \#5 & $\mathrm{F}$ & 65 & Classical & $\mathrm{DQ} 2+{ }^{\circ}$ & 11 & 65 & Small bowel carcinoma & Alive, 76 yrs \\
\hline$\# 6$ & $\mathrm{~F}$ & 55 & Classical & $\mathrm{DQ} 2+$ & 7 & 59 & RCD type 1 & Alive, 66 yrs \\
\hline
\end{tabular}

$E A T C L$, enteropathy associated T-cell lymphoma; $R C D$, refractory celiac disease.

${ }^{\circ} \mathrm{DQ} 2$ homozygosis (DQB1 ${ }^{*} 0201$ on both chromosomes) was established in case \#1, \#3 and \#5. 
screening. Interestingly, the age at $\mathrm{CD}$ diagnosis was significantly lower in subclinical than in symptomatic $\mathrm{CD}$, thus suggesting that serological screening detects CD earlier than symptoms.

Our series confirmed that IgA anti-TG2 were more sensitive than IgA EmA for the diagnosis of CD [2]. Other important findings included that IgA EmA positivity was never found in cases without IgA anti-TG2 [22]; about two thirds of the IgA TG2/EmA negative cases had IgA deficiency (and tested positive for IgG anti-TG2/DGP) [17] and, finally, that seronegative CD was identified only in a small subset of patients (1.4\%) [23]. Seronegative patients showed peculiar aspects not fully reported in previous studies [24]. First, compared to seropositive CD, seronegative disease was significantly associated with a classical phenotype. Thus, in all malabsorptive patients a diagnosis of $C D$ should be always ruled out by small bowel biopsy regardless an unsupportive serological profile. Secondly, seronegative CD was characterized by a more pronounced prevalence of the female gender (F/M 4.5:1) and a significantly higher median age at diagnosis (49 years) than seropositive CD (F/M 3.5:1 and 36 years). Thirdly, a close association with autoimmune disorders including primary biliary cirrhosis, autoimmune gastritis, Hashimoto's thyroiditis, peripheral neuropathy and gluten ataxia was found in seronegative patients. Finally, a proportion of otherwise seronegative $\mathrm{CD}$ patients tested positive for IgG AGA, a notoriously aspecific marker of CD [25], which, however, in the presence of villous atrophy may be clinically useful to address the diagnosis [26].

Compared to previous studies showing frequent flat mucosa [27], our data showed that only $62 \%$ of CD patients had severe intestinal damage (type 3b, 3c), whereas partial atrophy (type 3a) was found in an increasing percentage of cases $(25 \%)$. The latter finding may be the result of early detection of $\mathrm{CD}$ in a stage when intestinal damage has not yet peaked. Furthermore, in parallel with partial intestinal atrophy, the number of potential CD cases (13\%) was also high. The possible disappearance of serological markers in patients with potential $\mathrm{CD}$ on a glutencontaining diet particularly in subclinical patients, suggests a cautionary approach before starting GFD [28]. Another aspect pertaining to histopathology is related to the new guidelines emanated by ESPGHAN. Following these criteria it is now possible to skip histopathologic evaluation and to establish CD diagnosis in symptomatic children and adolescents testing positive for high titer anti-TG2 (more than ten folds above the cut-off) and confirmed by EmA and HLA-DQ2 and/or -DQ8 positivity [29]. Our series indicates that the ESPGHAN criteria, although quite interesting and certainly useful in the pediatric age, cannot be applied in adult CD cases [30,31]. In fact, a minority of cases with high titer anti-TG2 ( $>10$ times the upper normal limit) had non-atrophic mucosa being classifiable as a potential $\mathrm{CD}$, implying that in adult patients a firm diagnosis should always be established by means of small intestinal biopsy.

Our data confirm and expand the concept that $\mathrm{CD}$ can be associated with a number of autoimmune diseases [32]. A possible explanation for this spread of autoimmunity occurring in $\mathrm{CD}$ may be the ubiquitous distribution of TG2 in many other organs and tissues besides the small bowel [33]. Our study indicated that the most frequent condition associated with CD was Hashimoto's thyroiditis, found in about in one fourth of cases, with half of them developing clinical hypothyroidism. Dermatitis herpetiformis and type $1 \mathrm{DM}$ were detected in $4 \%$ and $3 \%$ of CD patients, respectively, both percentages in line with previous studies $[34,35]$. Concerning type $1 \mathrm{DM}$, previous data have shown that it rarely occurs in CD patients on a strict GFD, suggesting that gluten withdrawal may exert a protective role [36]. Brain and liver autoimmune disorders were closely associated with $C D$ as shown by gluten ataxia, peripheral neuropathy, epilepsy (notably resistant to pharmacologic treatment), primary biliary cirrhosis and autoimmune hepatitis identified in our CD patients [37-39]. Concerning connective tissue disorders our data confirmed that Sjögren syndrome and, to a lesser extent, systemic sclerosis were closely related to CD $[40,41]$, whereas, as previously reported, systemic lupus erythematosus and rheumatoid arthritis were rarely detected in $\mathrm{CD}[42,43]$. As previously demonstrated, Down and, to a lower extent, Turner syndrome were the two chromosomal disorders most commonly associated with $\mathrm{CD}[44,45]$.

An emerging entity is the non-responsive $C D$, which includes patients with an unsatisfactory response to GFD [46]. In our study we evaluated the response to GFD in 654 CD patients, followed-up for a period ranging from 18 months to 14 years. About $20 \%$ of them were labeled as non-responsive CD due to poor compliance to GFD, functional gastrointestinal disorders (e.g. GERD and irritable bowel syndrome) as well as food intolerance, e.g. to lactose. Another cause of non-responsive CD reported in the literature, i.e. CD misdiagnosis, was not identified in our series since all patients had been diagnosed according to well-established criteria [47]. The lack of response to GFD can be also due to the onset of complications in the natural course of $\mathrm{CD}$. For many years the frequency of complicated $\mathrm{CD}$ has been overestimated with data ranging up to $10 \%$ of the total number of celiac patients. Recent data, however, clearly demonstrated that complications occur in about $1 \%$ of $C D$ patients $[18,48]$ and, in the present study, only $0.9 \%$ of $\mathrm{CD}$ patients developed a complication including 3 cases of refractory CD, 2 small bowel carcinoma and 1 case of EATCL. The risk for the development of complications was higher in patients with a late recognition of $\mathrm{CD}$ and with a significant diagnostic delay. Complicated CD showed a significantly higher 
median age at diagnosis than non-complicated CD. Moreover, the occurrence of complications in $\mathrm{CD}$ patients was significantly related with an onset of $\mathrm{CD}$ characterized by the classical form with diarrhea and malabsorption, suggesting that non-classical and subclinical forms are at a lower risk of developing complications. CD patients with HLA-DQ2 homozygosis display a higher risk of developing complications [49]. Surprisingly, the prognosis of complicated CD in our series was better than expected with 5 of the 6 patients still alive after a mean follow-up of 10 years.

Possible limitations of this study concerned its retrospective nature which might have biased the data analysis as well as the lack of information on pediatric cases of $\mathrm{CD}$.

\section{Conclusions}

In conclusion, this study detailed the clinical features, serology and histopathological data in a very large series of adult $\mathrm{CD}$ patients diagnosed in a single referral center over a 15 year time frame. The results of this series corroborated and expanded previous evidence regarding: $i$ ) the clinical presentation of $\mathrm{CD}$ according to recently defined criteria (i.e. non-classical and subclinical prevailed over the classical forms); $i i$ ) the possibility of establishing an early diagnosis (i.e. when the disease is still in a preclinical/ paucisymptomatic stage), hence justifying an increased number of potential CD cases; iii) the different serological and histological patterns of the disease, which can help in the diagnostic work-up; and $i v$ ) the identification of autoimmune disorders commonly associated with CD. Finally, the follow-up of our $\mathrm{CD}$ patients showed that a high proportion of cases (about 20\%) could be labeled as nonresponsive $\mathrm{CD}$, mainly because of low compliance to GFD or concomitant functional gastrointestinal disorders. The lack of responsiveness can be related to complications, which, although rare, require an early diagnosis in order to avoid a poor outcome.

\section{Competing interests}

Roberto De Giorgio is recipient of grants from 'Italian Ministry of University and Research' and 'Fondazione del Monte di Bologna e Ravenna', Bologna, Italy. This work was supported by Ricerca Finalizzata RER2009 (Ita-MNGIE), Ministry of Health, and the Italian Ministry of University and Research (PRIN/COFIN 2009MFSXNZ_002).

\section{Authors' contributions}

Study concept and design: UV, GC, RDG; acquisition of data: GC, UV, RDG, VS; analysis and interpretation of data: UV, GC, RDG; drafting of the manuscript: UV, RDG, GC, VS; critical revision of the manuscript for important intellectual content: VS, UV, GC, RDG; statistical analysis: GC, UV, RDG, VS; obtained funding: RDG; material support: UV, GC, VS, RDG; study supervision: UV, GC, RDG, VS. All authors read and approved the final manuscript.

\section{Acknowledgements}

The authors are indebted with Prof. Kerry Rhoden of the Medical Genetic Unit, St. Orsola-Malpighi University Hospital, Bologna, Italy, for insightful comments to their paper and valuable editing of the English language. Also, they wish to thank Prof. Giampaolo Bianchi for his valuable help on statistical analysis.
Received: 16 September 2014 Accepted: 28 October 2014

Published online: 18 November 2014

\section{References}

1. Volta U, Villanacci V: Celiac disease: diagnostic criteria in progress. Cell Mol Immunol 2011, 8:96-102.

2. Fasano A, Catassi C: Clinical practice: Celiac disease. N Engl J Med 2012, 367:2419-2426.

3. Dieterich W, Ehnis T, Bauer M, Donner P, Volta U, Riecken EO, Schuppan D: Identification of tissue transglutaminase as the autoantigen of celiac disease. Nat Med 1997, 3:797-801.

4. Karell K, Louka AS, Moodie SJ, Ascher H, Clot F, Greco L, Ciclitira PJ, Sollid LM, Partanen J, European Genetics Cluster on Celiac Disease: HLA types in celiac disease patients not carrying the $\mathrm{DQA} 1{ }^{*} 05-\mathrm{DQB} 1{ }^{*} 02(\mathrm{DQ} 2)$ heterodimer: results from the European Genetics Cluster on Celiac Disease. Hum Immunol 2003, 64:469-477.

5. Ivarsson A, Hernell O, Stenlund H, Persson LA: Breast-feeding protects against celiac disease. Am J Clin Nutr 2002, 75:914-921.

6. Norris JM, Barriga K, Hoffenberg EJ, Taki I, Miao D, Haas JE, Emery LM, Sokol RJ, Erlich HA, Eisenbarth GS, Rewers M: Risk of celiac disease autoimmunity and timing of gluten introduction in the diet of infants at increased risk of disease. JAMA 2005, 293:2343-2351.

7. Ludvigsson JF, Fasano A: Timing of introduction of gluten and celiac disease risk. Ann Nutr Metab 2012, 60:22-29.

8. Pozo-Rubio T, Olivares M, Nova E, De Palma G, Mujico JR, Ferrer MD, Marcos A, Sanz Y: Immune development and intestinal microbiota in celiac disease. Clin Dev Immunol 2012, 2012:654143.

9. Chorzelski TP, Sulej J, Tchorzewska H, Jablonska S, Beutner EH, Kumar V: IgA class endomysium antibodies in dermatitis herpetiformis and coeliac disease. Ann N Y Acad Sci 1983, 420:325-334.

10. Dieterich W, Laag E, Schöpper H, Volta U, Ferguson A, Gillett H, Riecken EO, Schuppan D: Autoantibodies to tissue transglutaminase as predictors of celiac disease. Gastroenterology 1998, 115:1317-1321.

11. Mustalahti K, Catassi C, Reunanen A, Fabiani E, Heier M, McMillan S, Murray L, Metzger MH, Gasparin M, Bravi E, Mäki M, Coeliac EU, Cluster, Project Epidemiology: The prevalence of celiac disease in Europe: results of a centralized, international mass screening project. Ann Med 2010, 42:587-595.

12. McGowan KE, Castiglione DA, Butzner JD: The changing face of childhood celiac disease in north america: impact of serological testing. Pediatrics 2009, 124:1572-1578.

13. Rampertab SD, Pooran N, Brar $\mathrm{P}$, Singh $\mathrm{P}$, Green $\mathrm{PH}$ : Trends in the presentation of celiac disease. Am J Med 2006, 119:355-e9-14.

14. Sharma M, Singh $P$, Agnihotri A, Das P, Mishra A, Verma AK, Ahuja A, Sreenivas V, Khadgawat R, Gupta SD, Makharia GK: Celiac disease: a disease with varied manifestations in adults and adolescents. J Dig Dis 2013, 14:518-525.

15. Ludvigsson JF, Leffler DA, Bai JC, Biagi F, Fasano A, Green PH, Hadjivassiliou M, Kaukinen K, Kelly CP, Leonard JN, Lundin KE, Murray JA, Sanders DS, Walker MM, Zingone F, Ciacci C: The Oslo definitions for coeliac disease and related terms. Gut 2013, 62:43-52

16. Oberhüber G, Granditsch G, Vogelsang H: The histopathology of coeliac disease: time for a standardized report scheme for pathologists. Eur J Gastroenterol Hepatol 1999, 11:1185-1194.

17. Villalta D, Tonutti E, Prause C, Koletzko S, Uhlig HH, Vermeersch P, Bossuyt $X$, Stern M, Laass MW, Ellis JH, Ciclitira PJ, Richter T, Daehnrich C, Schlumberger W, Mothes T: IgG antibodies against deamidated gliadin peptides for diagnosis of celiac disease in patients with IgA deficiency. Clin Chem 2010, 56:464-468.

18. Biagi F, Gobbi P, Marchese A, Borsotti E, Zingone F, Ciacci C, Volta U, Caio G, Carroccio A, Ambrosiano G, Mansueto P, Corazza GR: Low incidence but poor prognosis of complicated coeliac disease: a retrospective multicentre study. Dig Liver Dis 2014, 46:227-230.

19. Alaedini A, Green PH: Narrative review: celiac disease: understanding a complex autoimmune disorder. Ann Intern Med 2005, 142:289-298.

20. Casella S, Zanini B, Lanzarotto F, Villanacci V, Ricci C, Lanzini A: Celiac disease in elderly adults: clinical, serological, and histological characteristics and the effect of a gluten-free diet. J Am Geriatr Soc 2012, 60:1064-1069.

21. Spiegel BM, DeRosa VP, Gralnek IM, Wang V, Dulai GS: Testing for celiac sprue in irritable bowel syndrome with predominant diarrhea: a costeffectiveness analysis. Gastroenterology 2004, 126:1721-1732. 
22. Sandström O, Rosén A, Lagerqvist C, Carlsson A, Hernell O, Högberg L, Ivarsson A: Transglutaminase IgA antibodies in a celiac disease mass screening and the role of HLA-DQ genotyping and endomysial antibodies in sequential testing. J Pediatr Gastroenterol Nutr 2013, 57:472-476.

23. DeGaetani M, Tennyson CA, Lebwohl B, Lewis SK, Abu Daya H, Arguelles Grande C, Bhagat G, Green PH: Villous atrophy and negative celiac serology: a diagnostic and therapeutic dilemma. Am J Gastroenterol 2013, 108:647-653.

24. Salmi T, Collin P, Korponay-Szabó IR, Laurila K, Partanen J, Huhtala H, Király R, Lorand L, Reunala T, Mäki M, Kaukinen K: Endomysial antibody-negative coeliac disease: clinical characteristics and autoantibody deposits. Gut 2006, 55:1746-1753.

25. Volta U, Fabbri A, Parisi C, Piscaglia M, Caio G, Tovoli F, Fiorini E: Old and new serological tests for celiac disease screening. Expert Rev Gastroenterol Hepatol 2010, 4:31-35.

26. Karnsakul W, Skitarelic K, Gillespie S, Arkachaisri T: Isolated positive antigliadin immunoglobin-A antibody in children with gastrointestinal symptoms. Turk J Gastroenterol 2012, 23:485-489.

27. Malamut G, Matysiak-Budnik T, Grosdider E, Jais JP, Morales E, Damotte D, Caillat-Zucman S, Brousse N, Cerf-Bensussan N, Jian R, Cellier C: Adult celiac disease with severe or partial villous atrophy: a comparative study. Gastroenterol Clin Biol 2008, 32:236-242.

28. Auricchio R, Tosco A, Piccolo E, Galatola M, Izzo V, Maglio M, Paparo F, Troncone R, Greco L: Potential celiac children: 9-year follow-up on a gluten-containing diet. Am J Gastroenterol 2014, 109:913-921.

29. Husby S, Koletzko S, Korponay-Szabó IR, Mearin ML, Phillips A, Shamir R, Troncone R, Giersiepen K, Branski D, Catassi C, Lelgeman M, Mäki M, Ribes-Koninckx C, Ventura A, Zimmer KP, ESPGHAN Working Group on Coeliac Disease Diagnosis; ESPGHAN Gastroenterology Committee; European Society for Pediatric Gastroenterology, Hepatology, and Nutrition: European Society for Pediatric Gastroenterology, Hepatology, and Nutrition guidelines for the diagnosis of coeliac disease. J Pediatr Gastroenterol Nutr 2012, 54:136-160.

30. Ludvigsson JF, Bai JC, Biagi F, Card TR, Ciacci C, Ciclitira PJ, Green PH, Hadjivassiliou M, Holdoway A, van Heel DA, Kaukinen K, Leffler DA, Leonard JN, Lundin KE, McGough N, Davidson M, Murray JA, Swift GL, Walker MM, Zingone F, Sanders DS, BSG Coeliac Disease Guidelines Development Group; British Society of Gastroenterology: Diagnosis and management of adult coeliac disease: guidelines from the British Society of Gastroenterology. Gut 2014, 63:1210-1228.

31. Caio G, Volta U: Coeliac disease: changing diagnostic criteria? Gastroenterol Hepatol Bed Bench 2012, 5:119-122

32. Kaukinen K, Mäki M: Coeliac disease in 2013: new insights in dietary-gluteninduced autoimmunity. Nat Rev Gastroenterol Hepatol 2014, 11:80-82.

33. Martucci S, Corazza GR: Spreading and focusing of gluten epitopes in celiac disease. Gastroenterology 2002, 122:2072-2075.

34. West J, Fleming KM, Tata LJ, Card TR, Crooks CJ: Incidence and prevalence of celiac disease and dermatitis herpetiformis in the UK over two decades: population-based study. Am J Gastroenterol 2014, 109:757-768.

35. Volta U, Tovoli F, Caio G: Clinical and immunological features of celiac disease in patients with type 1 diabetes mellitus. Expert Rev Gastroenterol Hepatol 2011, 5:479-487.

36. D’Annunzio G, Giannattasio A, Poggi E, Castellano E, Calvi A, Pistorio A, Barabino A, Lorini R: $\beta$-cell autoimmunity in pediatric celiac disease: the case for routine screening? Diabetes Care 2009, 32:254-256.

37. Volta U, Rodrigo L, Granito A, Petrolini N, Muratori P, Muratori L, Linares A, Veronesi L, Fuentes D, Zauli D, Bianchi FB: Celiac disease in autoimmune cholestatic liver disorders. Am J Gastroenterol 2002, 97:2609-2613.

38. Vajro P, Paolella G, Maggiore G, Giordano G: Pediatric celiac disease, cryptogenic hypertransaminasemia, and autoimmune hepatitis. J Pediatr Gastroenterol Nutr 2013, 56:663-670.

39. Volta U, De Giorgio R: Gluten sensitivity: an emerging issue behind neurological impairment? Lancet Neurol 2010, 9:233-235

40. Itanen S, Collin P, Korpela M, Holm K, Partanen J, Polvi A, Mäki M: Celiac disease and markers of celiac disease latency in patients with primary Sjögren's syndrome. Am J Gastroenterol 1999, 94:1042-1046.

41. Rosato E, De Nitto D, Rossi C, Libanori V, Donato G, Di Tola M, Pisarri S, Salsano F, Picarelli A: High incidence of celiac disease in patients with systemic sclerosis. J Rheumatol 2009, 36:965-969.

42. Francis J, Carty JE, Scott BB: The prevalence of coeliac disease in rheumatoid arthritis. Eur J Gastroenterol Hepatol 2002, 14:1355-1356.
43. Marai I, Shoenfeld Y, Bizzaro N, Villalta D, Doria A, Tonutti E, Tozzoli R: $\lg A$ and $\lg$ G tissue transglutaminase antibodies in systemic lupus erythematosus. Lupus 2004, 13:241-244.

44. Mårild K, Stephansson O, Grahnquist L, Cnattingius S, Söderman G Ludvigsson JF: Down syndrome is associated with elevated risk of celiac disease: a nationwide case-control study. J Pediatr 2013, 163:237-242.

45. Dias Mdo C, Castro LC, Gandolfi L, Almeida RC, Córdoba MS, Pratesi R: Screening for celiac disease among patients with Turner syndrome in Brasília, DF, midwest region of Brazil. Arq Gastroenterol 2010, 47:246-249.

46. Leffler DA, Dennis M, Hyett B, Kelly E, Schuppan D, Kelly CP: Etiologies and predictors of diagnosis in nonresponsive celiac disease. Clin Gastroenterol Hepatol 2007, 5:445-450

47. Biagi F, Bianchi PI, Campanella J, Zanellati G, Corazza GR: The impact of misdiagnosing celiac disease at a referral centre. Can J Gastroenterol 2009, 23:543-545.

48. Roshan B, Leffler DA, Jamma S, Dennis M, Sheth S, Falchuk K, Najarian R, Goldsmith J, Tariq S, Schuppan D, Kelly CP: The incidence and clinical spectrum of refractory celiac disease in a north american referral center. Am J Gastroenterol 2011, 106:923-928.

49. Biagi F, Bianchi PI, Vattiato C, Marchese A, Trotta L, Badulli C, De Silvestri A Martinetti M, Corazza GR: Influence of HLA-DQ2 and DQ8 on severity in celiac disease. J Clin Gastroenterol 2012, 46:46-50.

doi:10.1186/s12876-014-0194-x

Cite this article as: Volta et al:: The changing clinical profile of celiac disease: a 15-year experience (1998-2012) in an Italian referral center. BMC Gastroenterology 2014 14:194.

\section{Submit your next manuscript to BioMed Central and take full advantage of:}

- Convenient online submission

- Thorough peer review

- No space constraints or color figure charges

- Immediate publication on acceptance

- Inclusion in PubMed, CAS, Scopus and Google Scholar

- Research which is freely available for redistribution

Submit your manuscript at www.biomedcentral.com/submit
C Biomed Central 